Utah State University

DigitalCommons@USU

The Bark Beetles, Fuels, and Fire Bibliography

Quinney Natural Resources Research Library,

S.J. and Jessie E.

1991

\title{
On the Temperature Distribution Inside a Tree Under Fire Conditions
}

\author{
J. J. Costa \\ L. A. Oliveira \\ D. X. Viegas \\ L. P. Neto
}

Follow this and additional works at: https://digitalcommons.usu.edu/barkbeetles

Part of the Forest Biology Commons, and the Forest Management Commons

\section{Recommended Citation}

Costa, J.J., Oliveria, L.A., Viegas, D.X., Neto, L.P., 1991. On the temperature distribution inside a tree under fire conditions. Int. J. Wildland Fire. 1(2), 87-96

This Article is brought to you for free and open access by the Quinney Natural Resources Research Library, S.J. and Jessie E. at DigitalCommons@USU. It has been accepted for inclusion in The Bark Beetles, Fuels, and Fire Bibliography by an authorized administrator of DigitalCommons@USU. For more information, please contact digitalcommons@usu.edu.

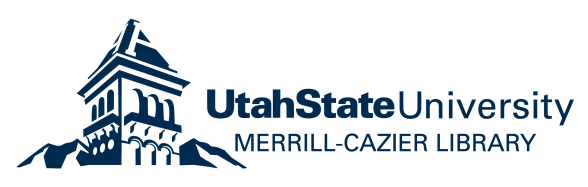




\title{
On the Temperature Distribution Inside a Tree Under Fire Conditions
}

\author{
J. J. Costa, L. A. Oliveira, D. X. Viegas and L. P. Neto \\ Departamento de Engenharia Mecânica - F.C.T.U.C., Universidade de Coimbra 3000 Coimbra, Portugal \\ Tel. 039-34339; Fax 039-22268
}

\begin{abstract}
A simple and efficient numerical scheme is presented for the prediction of temperature field distribution inside a tree trunk subjected to ground fire conditions. The trunk is modelled by a cylinder of circular cross section and unit length, through which the time-dependent heat conduction equation is numerically integrated. The model is partly validated in laboratory and then applied to the case of a prescribed ground fire inside a Pinus pinaster stand.
\end{abstract}

Keywords: Temperature; Modelling; Resistance; Bark; Physics

\section{Introduction}

The resistance of tree tissues to prescribed or wild forest fires is a question of primary concern to both the protection authorities and the research community. Serious damage or even death may occur as a result of crown scorch, cambium damage or heating within the soil. Most frequently, the effect of each of these factors upon tree ability to withstand fire conditions has been the object of separate studies.

Several attempts have been made to understand the way heat is transferred from fire flames to the interior of a burned trunk. Among others, those of Kayll (1963), Hare (1965), Vines (1968), Gill and Ashton (1968), De Ronde (1982, 1988), Costa et al. (1988) and Rego and Rigolot (1989) are worthy of mention. A crucial point is the temperature evolution inside the bark and particularly at the cambium, for which a definition of lethal conditions is now commonly accepted.

Theoretical predictions of such a heat transfer process are thus most helpful in establishing how this complex phenomenon correlates with fire conditions and tree characteristics. Calculations on the temperature field distribution across the bark of a trunk subjected to fire were made by Vines (1968) and more recently by Rego and Rigolot (1989) through one-dimensional models where thermal diffusivity is introduced as a known pa- rameter. This is a simple and attractive yet somehow restrictive kind of approach. In fact, it requires an inner boundary condition for temperature inside the trunk, where it is not known a priori (particularly for trees of small diameter); besides it does not take into account the fact that the temperature at a specific location inside a tree is actually influenced by the temperature distribution at the whole bark surface, which is highly irregular under fire conditions. In a recent preliminary work, Costa et al. (1988) developed a simple and efficient numerical procedure to calculate the temperature distribution within the whole cross section of a trunk exposed to fire conditions. A solution was obtained for the discretized version of the time-dependent heat conduction equation, expressed in polar coordinates, where the irregular character of the thermal peripheral conditions was accounted for. Bark and wood were specified in the model through the corresponding values of density, specific heat and thermal conductivity, and radial dimensions. Sample time-averaging temperatures at the bark surface were also measured in a prescribed fire inside a Pinus pinaster stand and then used as the only boundary conditions needed for the theoretical predictions. A good qualitative agreement was observed between the calculated results and those obtained through experiments reported in the available bibliography. However, further experimental validation was necessary for the predictions to be used with confidence in a wide range of practical situations.

In the present work, measured temperature profiles are reported for a section of a Pinus pinaster tree under laboratory-simulated fire conditions. Thermocouples were positioned at several angular locations in the outer bark and also at the cambium and wood. Parallel theoretical predictions were made for exactly the same conditions, thus seeking the expected code validation. Systematic comparisons were made and a good agreement was seen to hold. The code was partly validated and then applied to calculate the time-varying temperature field distribution inside a tree trunk subjected to a controlled ground fire in a Pinus pinaster stand. 


\section{Theoretical Predictions}

\subsection{Mathematical model}

When a tree trunk is exposed to a controlled or a wild fire a number of complex heat flow mechanisms may be involved in its response to the external adverse conditions: heat conduction inside the trunk, convective and radiative heat transfer at the outer bark surface or even a physiological response through vertical or horizontal movements in the tree tissues. Among all these factors, heat conduction is by far the most important and the others may be comparatively neglected in a first approximation (Reynolds (1939), Vines (1968)). Conservation of thermal energy for a unit volume is thus represented by the equation (see e.g. Bird et al. (1960)):

$$
\rho c \frac{\partial T}{\partial t}-\operatorname{div}(k \operatorname{grad} T)-S=0
$$

where $\rho, c$ and $k$ stand for density, specific heat and heat conductivity, respectively, $T$ is the temperature at time $t$ and $S$ is a unit volume energy source or sink.

Within the trunk region most directly affected by flames, vertical temperature gradients are much weaker than those observed in a direction perpendicular to the axis and will be ignored for the present purposes. The trunk is thus viewed as an infinitely long cylinder of circular cross section, of which a section of unit length will be considered in the following analysis. Polar coordinates are then adopted and equation (2.1) takes the form:

$$
p c \frac{\partial T}{\partial t}=\frac{1}{r} \frac{\partial}{\partial r}\left(r k \frac{\partial T}{\partial r}\right)+\frac{1}{r} \frac{\partial}{\partial \theta}\left(\frac{k}{r} \frac{\partial T}{\partial \theta}\right)+S
$$

where the position of an elemental volume is identified by its radial and angular coordinates $r$ and $\theta$, respectively.

Initial conditions for integration of expression (2.2) are set through a uniform ambient temperature distribution $T=T_{a}$ :

$$
T(r, \theta, 0)=T_{a}
$$

Boundary conditions are either of the Dirichlet type:

$$
T\left(r_{0}, \theta, t\right)=T_{0}(\theta, t)
$$

or of the Neumann type, where the normal temperature gradients are imposed at the external radius $r_{0}$ of the cross section through a specified boundary heat flux. Dirichlet and Neumann type boundary conditions are introduced in the model through the source term $S$ of equation (2.2), as shown in section 2.3. In the same equation, bark and wood are characterized by the corresponding values of $\rho, c$ and $k$, used as input for the model. Moisture content of wood is implicitly accounted for through its influence upon those thermodynamic properties, which are experimentally obtained as described later in section 4.1. Moisture content of bark is not directly taken into account.

\subsection{Numerical solution procedure}

Integration of the transient heat conduction equation was performed after modification of an existing twodimensional algorithm in order to include polar coordinates. The partial differential equation was discretized using the finite volume method (see Patankar(1980)). A grid covering the relevant domain is formed where each node is surrounded by an elemental control volume through which the equation is integrated. Heat flux between two adjacent control volumes is calculated at their common interface, thus ensuring local and global conservation of energy.

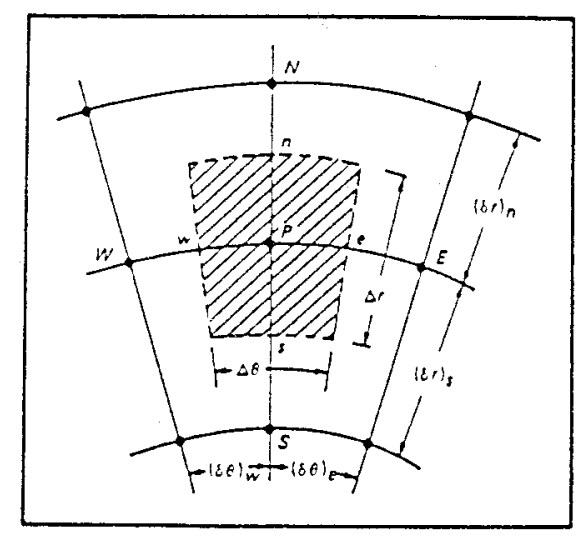

Figure 2.1 - Grid control volume

A control volume surrounding a nodal point $P$ of coordinates $(r, \theta)$ is schematically shown in figure 2.1. The volume faces are located midway between point $P$ and its four neighbours. Subscripts $P, E, W, N, S$ and $e$, $w, n, s$ will thus be assigned to values of the field variables at the nodes and at the cell boundaries, respectively. According to figure 2.1 the volume of a cell of unit width is approximately given by:

$$
\Delta V=0.5\left(r_{n}+r_{s}\right) \Delta \theta \Delta r
$$

The time domain is also discretized through a subdivision into time steps $\Delta t$. 
Space and time integration of equation (2.2) through the control volume of figure 2.1 and between instants $t$ and $t+\Delta t$ yields:

$$
\begin{gathered}
\rho c \int_{t}^{t+\Delta t} \int_{s}^{n} \int_{w}^{e} \frac{\partial T}{\partial t} r d \theta d r d t=\int_{t}^{t+\Delta t} \int_{s}^{n} \int_{w}^{e} \frac{\partial}{\partial r}\left(r k \frac{\partial T}{\partial r}\right) d \theta d r d t+ \\
+\int_{t}^{t+\Delta t} \int_{s}^{n} \int_{w}^{e} \frac{\partial}{\partial \theta}\left(\frac{k}{r} \frac{\partial T}{\partial \theta}\right) d \theta d r d t+ \\
+\int_{t}^{t+\Delta t} \int_{s}^{n} \int_{w}^{e}\left(S_{c}+S_{p} T\right) r d \theta d r d t
\end{gathered}
$$

where the coefficients $S_{C}$ and $S_{p}$ are obtained by rearranging the energy source term of (2.2) into a linear function of $T$ (see Patankar (1980)):

$$
S=S_{c}+S_{P} T
$$

This linearization is formally needed because the discretization equation (2.9) will be solved by the techniques for linear algebraic equations.

Additional assumptions are now necessary to evaluate the integrals in expression (2.6). For the transient and source terms the $T$ value of each grid node is seen as representative of the temperature at the whole surrounding control volume; the diffusive fluxes are calculated under the assumption of linear temperature variation between adjacent grid points; finally a fully implicit formulation is adopted for time integration, where $T^{\circ}$ stands for the temperature at the step immediately preceding the current one. In other words, $T$ in the control volume of figure 2.1 is assumed to vary with time from $t$ to $t+\Delta t$ in a way that can be generalized through a weighting procedure between the two time steps:

$$
\left(\int_{t}^{t+\Delta t} T d t\right)_{p} \approx\left[f T_{p}+(1-f) T_{p}^{0}\right] \Delta t
$$

the weighting factor $f$ being set here as equal to one.

When these assumptions are implemented in equation (2.6) the following expression results:

$$
a_{P} T_{P}=a_{E} T_{E}+a_{W} T_{W}+a_{N} T_{N}+a_{S} T_{S}+b
$$

where:

$$
a_{E}=\frac{k_{e} \Delta r}{r_{e}(\delta \theta)_{e}}, a_{W}=\frac{k_{w} \Delta r}{r_{w}(\delta \theta)_{w}}, a_{N}=\frac{k_{n} r_{n} \Delta \theta}{(\delta r)_{n}}, a_{S}=\frac{k_{s} r_{s} \Delta \theta}{(\delta r)_{s}}
$$

$$
\begin{aligned}
a_{p}^{0}=\frac{\rho c \Delta V}{\Delta t}, & b=S_{c} \Delta V+a_{P}^{0} T_{P}^{0}, a_{P}=a_{E}+a_{W}+a_{N}+ \\
& +a_{S}+a_{P}^{0}-S_{P} \Delta V
\end{aligned}
$$

Application of (2.9) to each grid node yields a system of simultaneous algebraic equations, to which a solution is iteratively obtained through a standard line-by-line procedure, followed by a tri-diagonal matrix algorithm, TDMA (see Smith (1978) and Gosman et al. (1985)).

The whole procedure starts with an initial guess for the entire temperature domain, thus allowing calculation of coefficients (2.10) and subsequent resolution of equation (2.9) for all grid nodes. Coefficients (2.10) may then be corrected by using the new temperature distribution and equation (2.9) solved again until convergence is attained. If this is the case the resulting temperature field is taken as the initial distribution to perform a similar calculation for the next time step $t+\Delta t$. The whole calculation procedure stops when a permanent regime (or alternatively a pre-set time level) is reached. Details concerning both the iteration scheme and the criteria used for convergence tests were those recommended by Gosman et al. (1985).

Approximate grid independence was ensured by using a mesh with $62 \times 62$ nodes, uniformly distributed along $\theta$ and gradually compressed with increasing $r$ in order to represent accurately the high temperature gradients that occur near the bark surface (see figure $4.5)$.

\subsection{Boundary conditions}

The grid is arranged in such a way that the bark surface coincides with the external surfaces of the boundary cells. In this way conservation of heat flux is ensured and boundary conditions are easily incorporated. According to this structure, temperature values at the nodes exterior to the domain are meaningless and so their link to the neighbouring interior ones has to be broken. This is accomplished by setting the relevant linking coefficient to zero. The correct expression for this coefficient is then calculated from the prescribed boundary condition and added to equation (2.9) through the source term.

This is illustrated in figure 2.2, where the coefficient $a_{N}$ is set to zero. Then a boundary heat flux $F_{B}\left(F_{n}=F_{B}\right)$ may be prescribed by adding the following contribution to the source term:

$$
S_{P}=0, S_{C}=F_{B}
$$

Alternatively a boundary temperature value $T_{B}$ may be assigned to the bark surface at that angular location. This is equivalent to prescribing a wall flux given by: 


$$
F_{n}=\frac{k_{n} r_{n} \Delta \theta}{(\delta r)_{n P}}\left(T_{B}-T_{P}\right)
$$

through the additional source:

$$
S_{P}=-\frac{k_{n} r_{n} \Delta \theta}{(\delta r)_{n P}}, S_{C}=\frac{k_{n} r_{n} \Delta \theta T_{B}}{(\delta r)_{n P}}
$$

Neumann-type boundary conditions may easily be incorporated in the code to allow for convective and radiative heat transfer at bark surface. In the present calculations only Dirichlet-type boundary conditions were imposed, where $T_{B}$ was obtained from experiments: laboratory measurements (figure 4.1 ) were used to validate the model and field measurements (figure 4.3) provided the boundary conditions for the remaining calculations.

\section{Experimental Methodology}

Various tests were conducted both in the laboratory and in the field in order to obtain realistic data to serve as input for validation of the mathematical model. All tests were made using $P$ inus pinaster trees, given the importance and extension of pine plantations in Portugal.

For the laboratory tests a fuel bed of approximately $3 \times 6 \mathrm{~m}^{2}$ was prepared in a large hall and a specimen of the trunk with a length of $1 \mathrm{~m}$ was placed in its center. The fuel used in these tests was dry straw with a layer depth of about $15 \mathrm{~cm}$. Fire was started along one of the smaller sides of the fuel bed.

The field tests were conducted on a flat terrain near the Lousã airfield, in a pine stand of adult trees spaced 10 to $15 \mathrm{~m}$ from each other. A rectangular plot of $4 \times 12 \mathrm{~m}^{2}$ was prepared around each tree and isolated from the other ground fuel by a safety line. Fire was started along a line perpendicular to the wind direction in order to obtain a plane flame front. Due to wind direction shifts during the tests this was not always achieved. In all tests

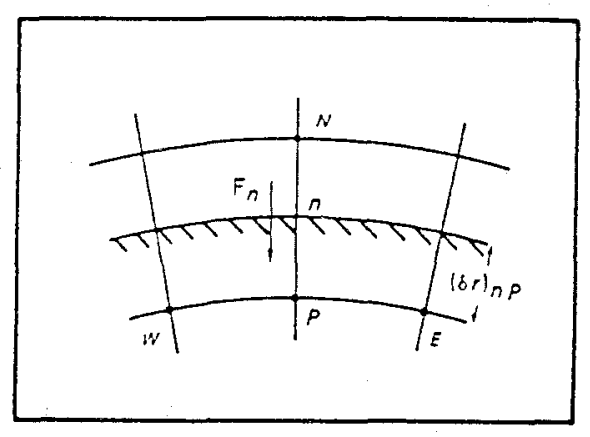

Figure 2.2 - Boundary conditions the trunks were previously equipped with thermocouples in order to obtain the temperature/time variation at various locations of the trunk. The thermocouples were of $K$ type, protected by a steel cover with a diameter of $4 \mathrm{~mm}$ and $10 \mathrm{~m}$ long. Some tests were performed in order to evaluate the effect of heatconduction through the steel cover on the temperature measurement. A Bunsen burner flame was placed under the steel cover at various distances from the tip of the thermocouple. No effect was detected when the flame was further than $10 \mathrm{~cm}$ from the tip.

No corrections were made to the temperature readings due to convection or radiation losses from the thermocouples. The convection losses in the laboratory tests should be particularly low due to the still condition of the air in the room. During the passage of the flame, radiation losses were also estimated to be very low, but after that, during the cooling process, the thermocouples exposed to the air will probably exhibit a faster temperature decay than the bark of the tree.

All thermocouples were placed on the same horizontal plane (trunk cross section) at about $30 \mathrm{~cm}$ from the ground. Four to six sensors were placed symmetrically around the trunk. A good contact of the thermocouple tip with the surface of the bark was assured by taking advantage of the bark roughness. To minimize conduction errors these thermocouples were placed vertically along the trunk. Some thermocouples were placed with their tip inside the trunk, either at the cambium or at other radii. For this purpose $4.5 \mathrm{~mm}$ holes were drilled in the trunk in order to reach the desired position.

The present mathematical model allows temperature/time variation to be calculated at the entire cross section. Therefore, comparison between numerical and experimental results can be established for validation purposes at any point of the section, provided its position and temperature are accurately measured. The actual position of the sensor tips was thus checked after the tests by cutting the trunk through the plane of the holes. For obvious reasons this procedure was only adopted with the trunk specimens used in the laboratory tests.

The authors experienced some difficulty in positioning the sensors in the cambium. One method that proved to be useful consisted in drilling a hole through the trunk and then use a wooden cap equal in length to the bark thickness to stop the thermocouple that was introduced from the opposite side of the trunk. The cap was then removed and the remaining hole was carefully filled with bark material.

The thermocouples were connected to a 16 channel data acquisition system DASH 16 that incorporates a reference temperature correction and includes calibration software for this type of thermocouples. The acquisiton rate was of one point every five seconds for all 
the channels simultaneously.

The duration of each test was of 60 to 90 minutes, although the burning of the plot was over usually 10 to 15 minutes after initiating the test.

\section{Results and Discussion}

\subsection{Validation of the theoretical model}

A partial validation of the present model was obtained through comparison of our numerical predictions with the corresponding laboratory results. For this purpose a Pinus pinaster trunk section was exposed to fire conditions while its surface, cambium and wood temperatures were monitored as described in section 3. Parallel numerical predictions were performed using a combination of measured and estimated thermodynamic properties for the calculation domain.

The weight of the specimen was determined and its volume measured to give a mean value for the density of wood $p_{w}$ (based on a wet volume and a wet weight):

$$
\rho_{w}=962.2 \mathrm{Kg} / \mathrm{m}^{3}
$$

The wood specific heat $c_{\mathrm{w}}$ and thermal conductivity $k_{\mathrm{w}}$ (along the trunk radial direction, where the most important temperature gradients are observed under fire conditions) were measured according to a procedure described in detail by Figueiredo et al. (1990). For this purpose, a constant-flux heating experiment was conducted in a cylindrical specimen of wood, $200 \mathrm{~mm}$ long and $70 \mathrm{~mm}$ in diameter, that had been previously machined out from the same tree trunk. The axial direction of the test cylinder was made to coincide with the trunk radial direction. Plastic bags and adhesive film were used to avoid loss of moisture before and during the experiment. Five thermocouples were radially inserted through small diameter holes and positioned at equally spaced locations along the cylinder centerline. The specimen was heated by thermal contact at one of its tips. Care was taken to ensure that the lateral surface of the cylinder was nearly adiabatic, thus rendering the heat flow roughly one-dimensional.

Once the temperature/time curves were recorded at each measuring point and the heat flux, as well as the specimen mass, were accurately known, a mean value for the wood specific heat $c_{\mathrm{w}}$ could be obtained through a simple energy balance averaging procedure.

A theoretical solution where $k_{w}$ is one of the inputs can be easily obtained for the transient one-dimensional heat conduction process inside the specimen. The correct value for the thermal conductivity of wood is found by a trial-and-error procedure, where the calculated tempera- tures must match the corresponding experimental measurements.

The following average values were obtained:

$$
\begin{aligned}
& C_{W}=4279 \mathrm{~J} / \mathrm{Kg} \cdot{ }^{\circ} \mathrm{C} \\
& k_{W}=0.36 \mathrm{~W} / \mathrm{m} .{ }^{\circ} \mathrm{C}
\end{aligned}
$$

The wood thermal diffusivity $\alpha_{w}=(k / \rho c)_{w}$ is thus $0.87 \times 10^{-7} \mathrm{~m}^{2} / \mathrm{s}$, approximately half the value indicated by Kollmann and Côté (1968): $1.7 \times 10^{-7} \mathrm{~m}^{2} / \mathrm{s}$. The authors believe that the relatively high moisture content of the present specimen ${ }^{1}$ is the mainly responsible factor for this discrepancy. Unfortunately, directmeasurements for the thermodynamic properties of bark could not be obtained with our measuring devices and the available literature does not provide complete and reliable information on the values needed, so they had to be estimated. A contribution received by courtesy of "Instituto Nacional de Investigação Agrária" (INIA) suggests for bark density $\rho_{b}$ :

$$
\rho_{b}=570 \mathrm{Kg} / \mathrm{m}^{3}
$$

Specific heat of bark $c_{b}$ was taken to vary with temperature according to the expression used by Koch (1972):

$$
c_{b}=1390.6-1.081 \mathrm{~T}+0.0215 \mathrm{~T}^{2} \mathrm{~J} / \mathrm{Kg} .{ }^{\circ} \mathrm{C}
$$

The best agreement between calculations and experiments was obtained by attributing to the thermal diffusivity of bark $\alpha_{b}$ a value which is one half the one used by Vines (1968), but closely approaches the measurements of Reifsnyder et al. (1967) for different pine species. This means that even though bark thickness is the most important single factor affecting its insulation capacity, the influence of structure, composition, density and moisture content cannot be ignored. The same conclusion was drawn by Davis (1959) and more recently by De Ronde (1982). The value $\alpha_{t}=0.65 \times 10^{-7} \mathrm{~m}^{2} / \mathrm{s}$ was thus adopted for the present bark specimen, the corresponding thermal conductivity $k_{\mathrm{b}}$ then following directly from the expression:

$$
k_{b}=(\alpha \rho c)_{b}
$$

\footnotetext{
${ }^{1}$ If $W_{i}$ stands for initial weight and $W_{d}$ for oven-dry weight, moisture content is here defined as m.c. $=\left(W_{i^{-}}\right.$ $\left.W_{d}\right) / W_{d}$. According to this definition, a value of m.c. $=88.3 \%$ was measured for the present wood specimen.
} 


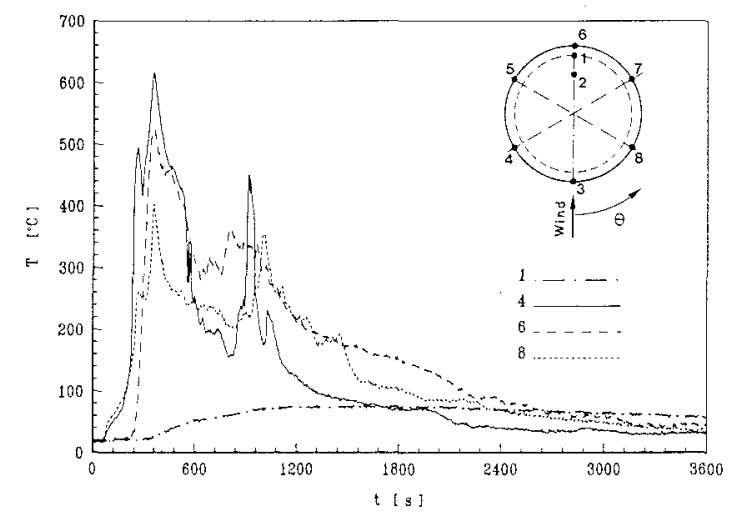

Figure 4.1 - Temperature as a function of time at the bark surface. $e=9 \mathrm{~mm}, d=229 \mathrm{~mm}$. Laboratory measurements.

together with (4.4) and (4.5). Owing to this adjustment, the present model should only be claimed as partly validated.

Once they were found, the input values of $\rho, c$ and $k$ for wood were considered not to vary with time. However, if adequate laws were available, the dependence of those properties upon time (through the timevarying temperature and/or moisture content at each spatial location) could be introduced in the model by a simple updating procedure, to be applied at each step of the discretized time domain. This is the case for $c_{b}$ through equation (4.5).

The average values measured for bark thickness $\underline{e}$ and diameter $\underline{d}$ of the test trunk were 9 and $229 \mathrm{~mm}$, respectively.

Measured temperatures at different locations of the test trunk subjected to laboratory fire conditions are shown in figure 4.1 as a function of time. The instant $t=0$ corresponds to the first moment at which any recorded temperature began to rise above ambient temperature. The complete test duration was $5400 \mathrm{~s}(90 \mathrm{~min})$ but no particular behaviour was observed beyond $4500 \mathrm{~s}$. The eight thermocouples were distributed as represented in the figure, the mean direction of flame propagation being taken as a reference for angular positions $\left(\theta=0^{\circ}\right)$. For the sake of clarity, only the information collected from thermocouples 1 (cambium), 4, 6 and 8 is shown.

A clear lack of symmetry with respect to the wind direction can be observed from comparing curves $T_{4}(t)$ and $T_{8}(t)$, thus indicating that the flames favoured a specific path around the trunk. This behaviour can also be observed in a video film in which the whole test was recorded. The lee side $\left(T_{6}\right)$ was also subjected to a very high temperature level. The cambial temperature at location 1 began to rise about $3 \min$ after $T_{6}$, then showing a somewhat irregular rise for nearly $30 \mathrm{~min}$ (see figure 4.2) until it reached a maximum of $75^{\circ} \mathrm{C}$ and decreased thereafter evenly to $60^{\circ} \mathrm{C}$ over a period of $45 \mathrm{~min}$.

Measured and predicted temperature/time variations are presented in figure 4.2 for two particular trunk locations: at the cambium $\left(T_{1}\right)$ and inside the wood $\left(T_{2}\right)$. The second position had a radial coordinate $r_{2}=87 \mathrm{~mm}$ (18.5 mm apart from the cambium). The cambial rate of heating was greater than its rate of cooling for in the latter case the temperature difference between cambium and bark surface was much lower (see curves 1 and 6 in figure 4.1). The experimental curves are relatively spread as a consequence of the gain characteristics of the A/D converter used in the data acquisition system.

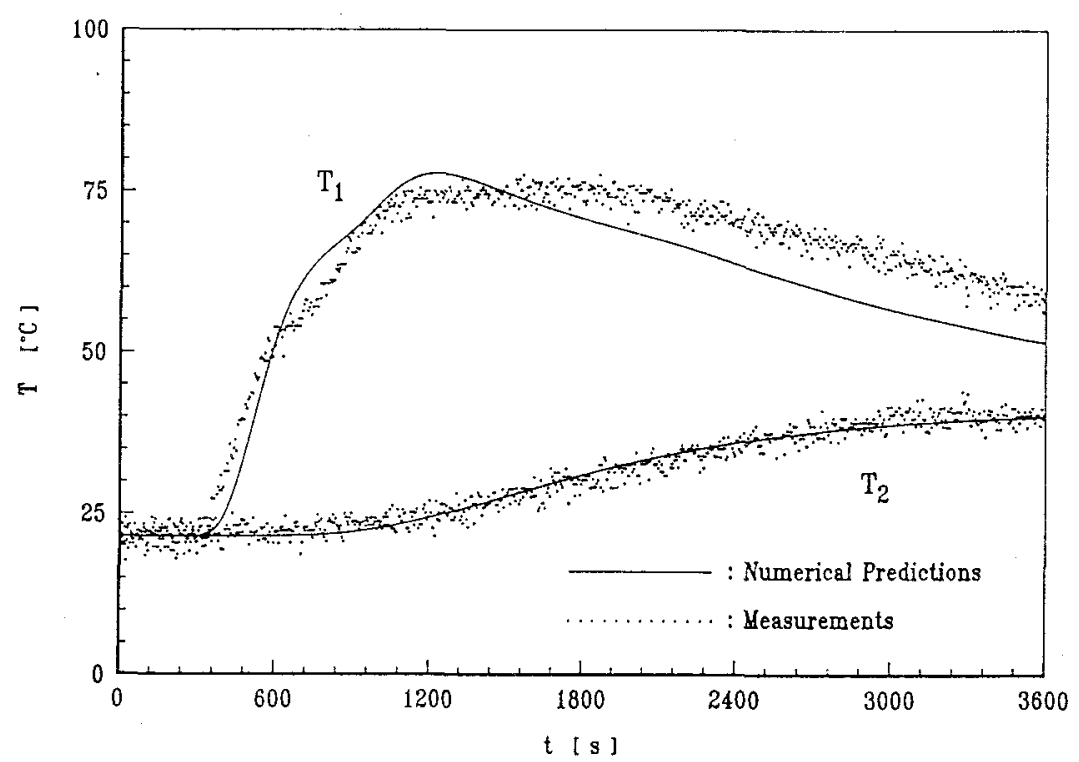

Figure 4.2 - Calculated and measured temperature/time traces at positions 1 and 2 of fig. 4.1 


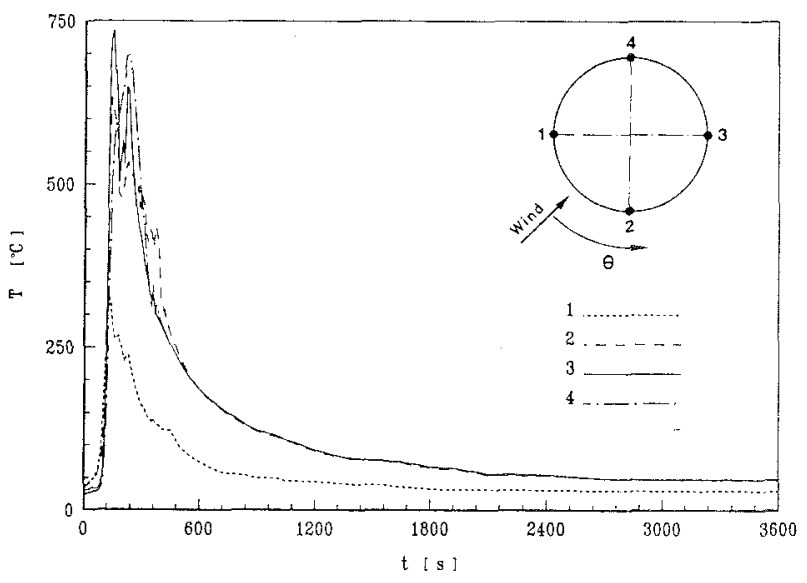

Figure 4.3 - Temperature as a function of time at the bark surface. $e=34 \mathrm{~mm}, d=318 \mathrm{~mm}$. Field measurements.

The calculated cambial temperature reaches its maximum somewhat before and decreases slightly faster than the measured one. This is probably connected with an actual variation of bark thermal diffusivity due to flame action, which is not accurately taken into account in the model. Except for these two features, correlation between theory and experiments is excellent.

\subsection{Application of the model to field fire conditions}

The partial validation thus obtained allowed the mathematical model to be used for the prediction of temperature distribution within the trunk of an actual tree subjected to field ground fire conditions. For this purpose field tests were carried out in a Pinus pinaster stand located at Lousã, as described in section 3.

Temperature/time traces at the surface of the monitored tree trunk are shown in figure 4.3. Mean values measured for the trunk diameter $\underline{d}$ and bark thickness $\underline{e}$ were 318 and $34 \mathrm{~mm}$, respectively. Asymmetry with respect to the mean wind direction is again noticed. Moreover, the lee side was exposed to the highest temperatures recorded, thus showing the effect of a great flow recirculation due to the wind action. This is not surprising, for wind speed was far more important in field than in laboratory experiments, where the air was almost still. The effect of flow recirculation upon the surface temperature distribution was also noticed in the works of Kayll (1963) and De Ronde (1982).

As in the preceding case measured surface temperatures were used as a boundary condition to predict the temperature field distribution within the trunk. For this purpose surface temperatures at intermediate angular locations were estimated by linear interpolation from the four values actually measured. The same distribution was also utilized in a first approximation as input for calculations relative to other trunk diameters and bark thicknesses. Thermodynamic properties of the laboratory test specimen were equally used in the numerical predictions for field conditions.

The angular temperature distribution calculated for the cambium at successive time levels is shown in figure 4.4. Both axes in the figure are divided into equal temperature increments of $10^{\circ} \mathrm{C}$, the dashed circle thus corresponding to a uniform initial temperature of $23^{\circ} \mathrm{C}$. The symbol standing for each time level is located at the angular position where temperature was maximum at that instant. One can thus see that after $15 \mathrm{~min}$ all maximum values were reached near $\theta=210^{\circ}$, again a sign of the influence that external recirculation exerts upon the cambial temperature distribution. The maximum temperature observed for $t=60 \mathrm{~min}$ (when the field test was stopped) was $32.3^{\circ} \mathrm{C}$ and occurred at $\theta=210^{\circ}$. Thereafter the cambium temperature would certainly not tend to increase (this is suggested through the predicted $T_{c}$ /time curve in figure 4.6.a), so we took the angular position $\theta=210^{\circ}$ as defining a "critical diameter".

For that critical diameter, the radial temperature distribution recorded at three time levels ( $t=20,40$ and $60 \mathrm{~min}$ ) is represented in figure 4.5 . The vertical bar located at $r=125 \mathrm{~mm}$ stands for cambium radius. The time-varying heat propagation from the trunk surface to its interior clearly illustrates the role of bark as an insulating protection for the cambial region.

The influence of bark thickness upon the temperature level within the peripheral trunk region may be analysed through figure 4.6, where predicted temperature/time traces are shown for three bark thicknesses and two radial locations: cambium $\left(T_{c}\right)$ and half bark thickness $\left(T_{m}\right)$. The field temperature measurements presented in figure 4.3 were adopted as boundary conditions for the three cases. For calculation purposes the two missing trunk diameters were estimated, assuming that a linear dependence between $\underline{d}$ and $\underline{e}$ applies. Figures (a), (b) and (c) correspond to the test bark thickness ( $\mathrm{e}=34 \mathrm{~mm}$, as in

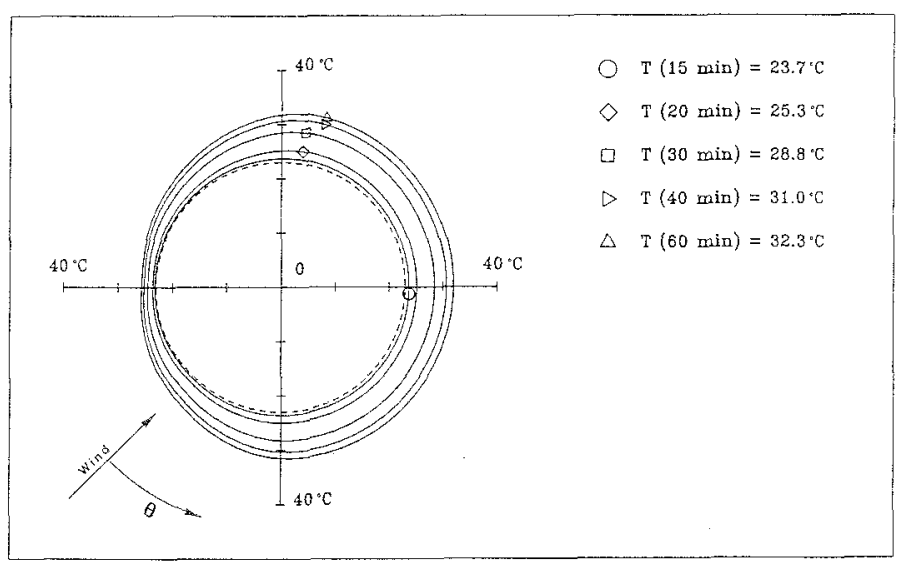

Figure 4.4 - Predicted time-variation of the cambium temperature. $e=34 \mathrm{~mm}, d=318 \mathrm{~mm}$. 


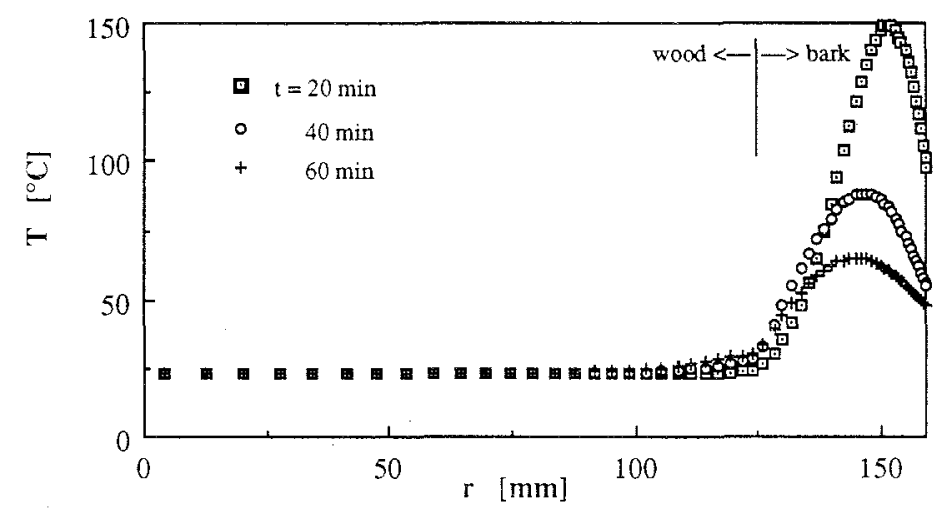

Figure 4.5 - Predicted radial evolution of the cambial temperature at the critical diameter for three time levels: $t=20,40,60 \mathrm{~min} . e=34 \mathrm{~mm}, d=318 \mathrm{~mm}$.

figures 4.3-5), two-thirds and half of that value, respectively. The highest cambium temperatures were, in the same order, $32.3,41.3$ and $52.1^{\circ} \mathrm{C}$. These values are all below the commonly accepted lethal level of $60^{\circ} \mathrm{C}$, thus indicating that irreversible injuries would probably not occur under such ground fire conditions. This conclusion is more optimistic than the one drawn in our preliminary work (Costa et al. (1988)), where the thermodynamic properties used for calculations were only based upon the available literature. A correct model may thus lead to unrealistic results if the adequate property values that apply to the precise conditions under analysis are not accurately known.

Even though the cases considered are not strictly the same, the time evolutions in this figure are in qualitative agreement with those obtained by Vines (1968) and Gill and Ashton (1968) for similar cases. The response time (necessary for cambium temperature to rise $1{ }^{\circ} \mathrm{C}$ above ambient temperature) was $16,7.9$ and $5.5 \mathrm{~min}$ for the three bark thicknesses in decreasing order, respectively. The corresponding mean rates of temperature rise were
0.36, 1.4 and $3.6^{\circ} \mathrm{C} / \mathrm{min}$. Cooling rate also increases with decreasing bark thickness. Comparison with figure 4.3 shows that exposure of the cambium to high temperature is much longer than exposure of bark to flame. It may even be noticed that $T_{c}$ continues to rise after flame removal. This inertial effect should be taken into account when evaluating the capacity of a tree to withstand fire conditions, for the lethal temperature decreases with increasing time of exposure to heat (Martin (1963)). As it was stressed above, heating was faster than cooling, a consequence of the lower gradients between cambium and surface that were observed in the latter case.

The time needed for cambium temperature to reach a certain reference value may give a good indication of bark insulating capacity. As the lethal temperature of 60 ${ }^{\circ} \mathrm{C}$ was never reached at the cambium, $30^{\circ} \mathrm{C}$ was the reference value adopted for the present case. In figure 4.7 the predicted time interval is plotted against bark thickness in a semi-logarithmic scale. Even though only three points are available, a linear type of dependence is quite apparent, as was already noticed in the work of Hare

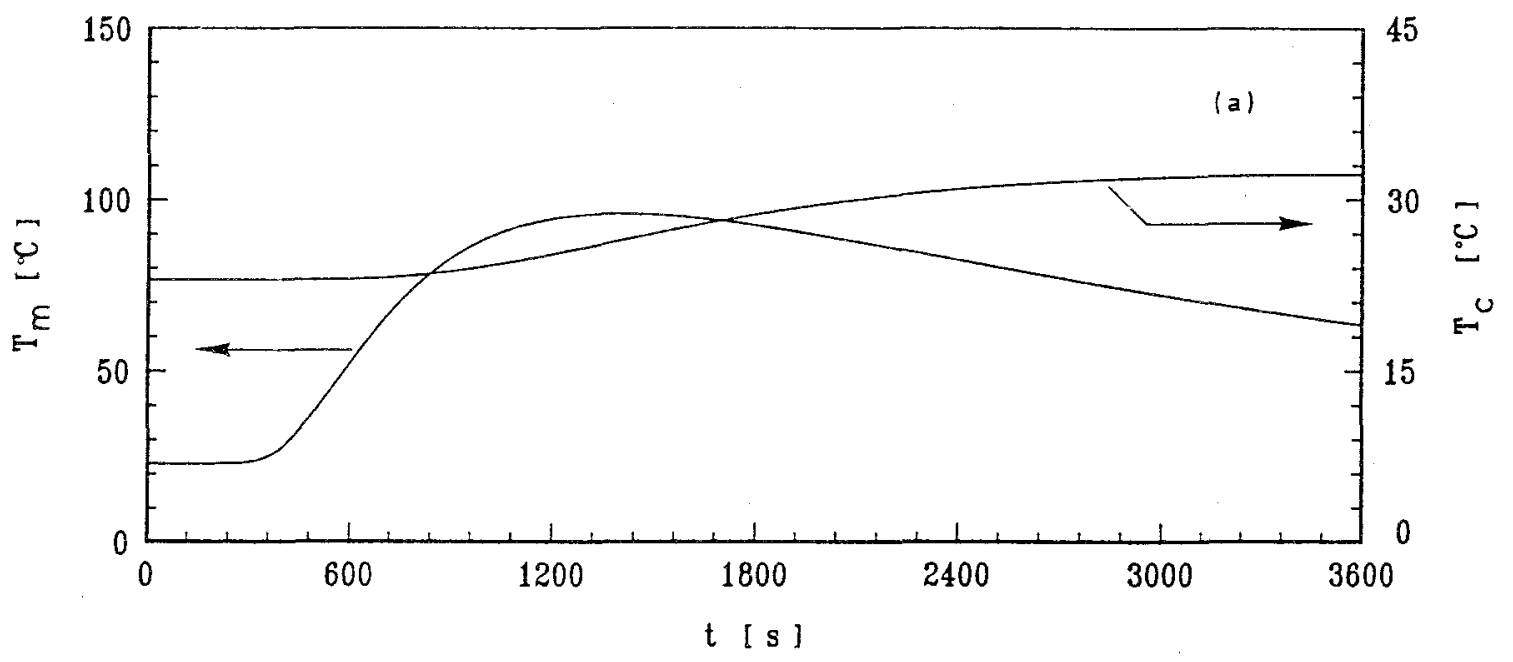




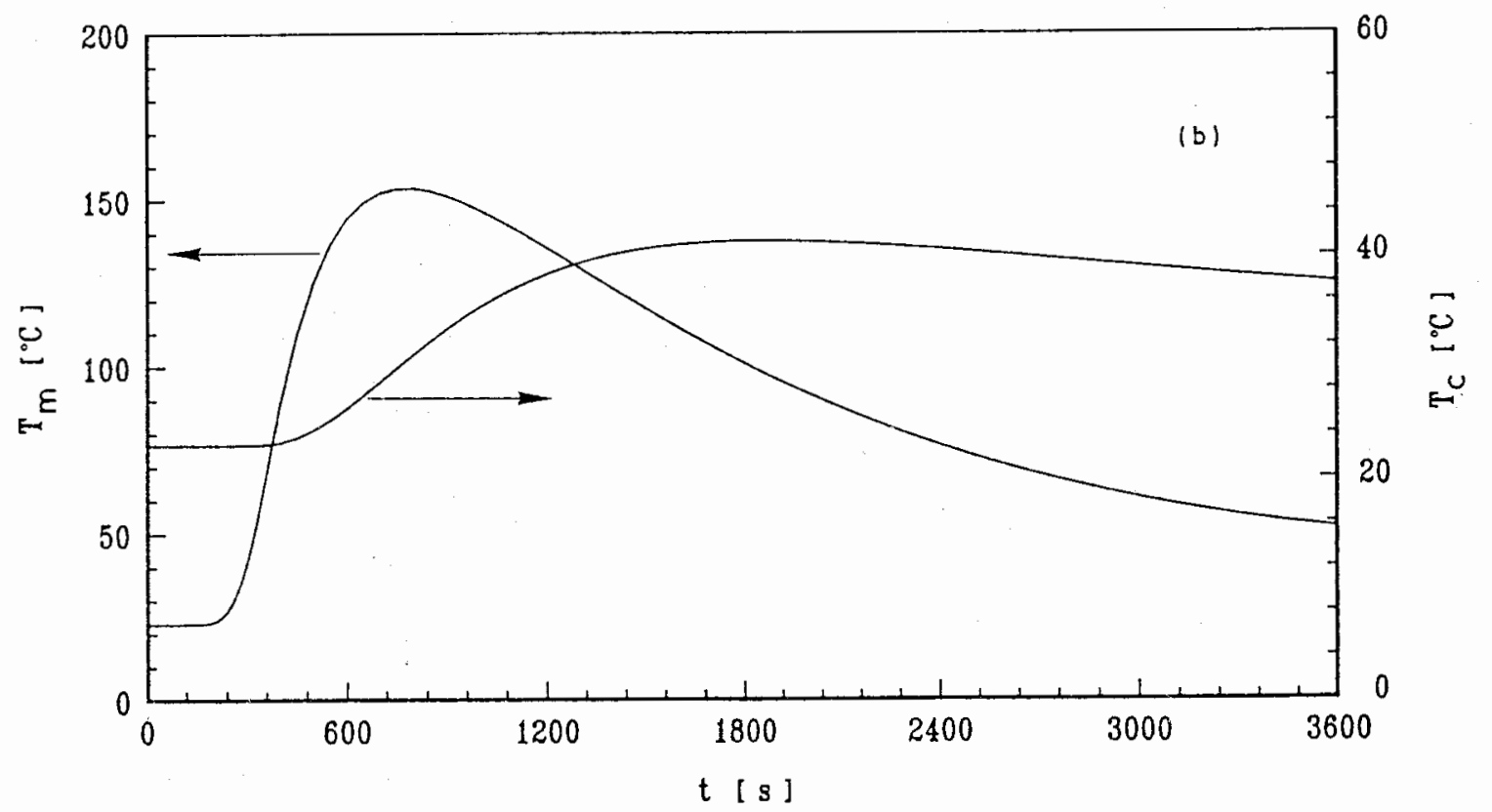

$(4-b)$

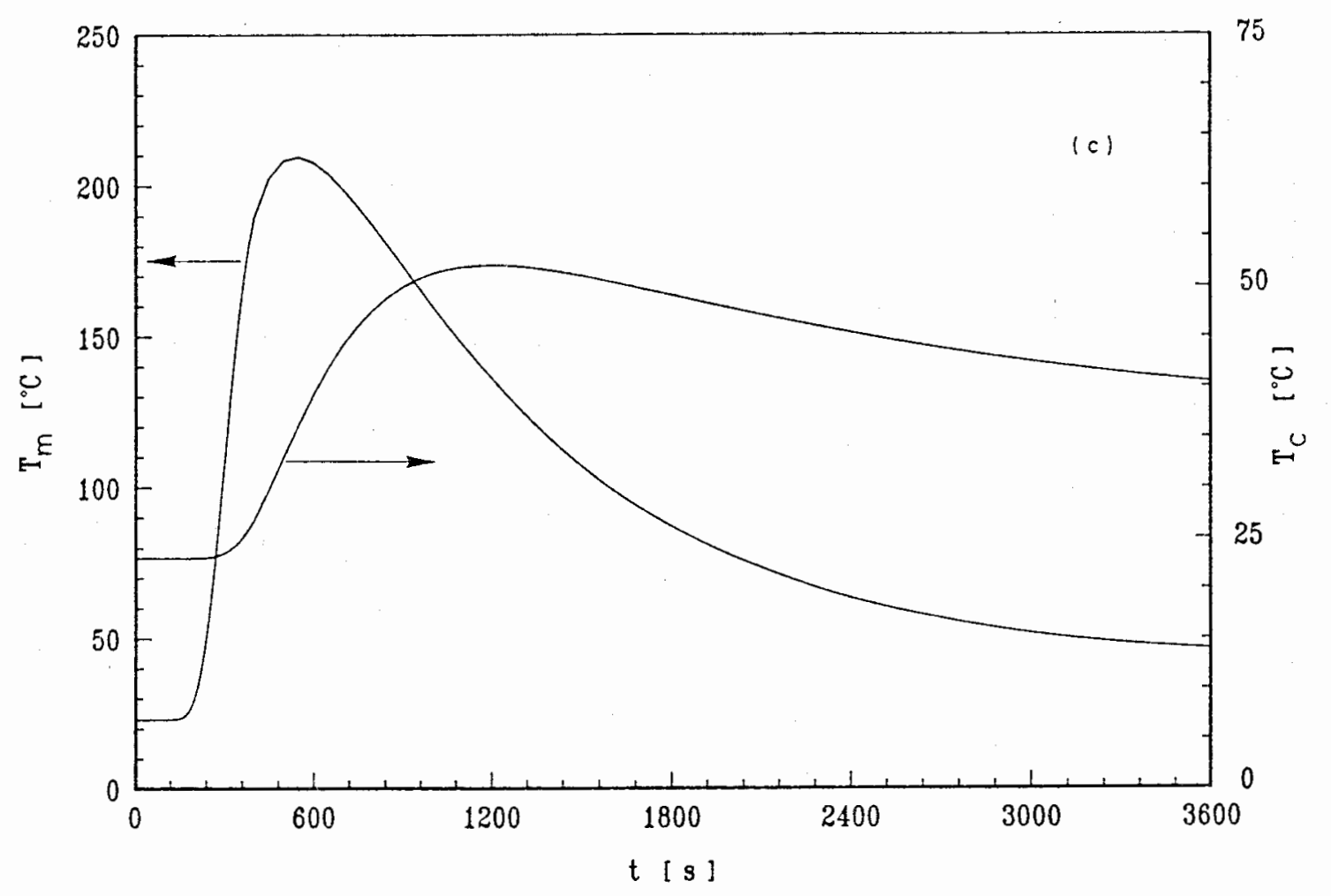

$(4-c)$

Figure 4.6 - Predicted temperature/time evolution at the critical diameter for two radial locations: cambium $(T)$ and half bark thickness $\left(T_{m}\right) .(a): e=34 \mathrm{~mm}, d=318 \mathrm{~mm} ;(b): e=23 \mathrm{~mm}, d=215 \mathrm{~mm}$; (c): $\mathrm{e}=17 \mathrm{~mm}, \mathrm{~d}=159$ mon. 


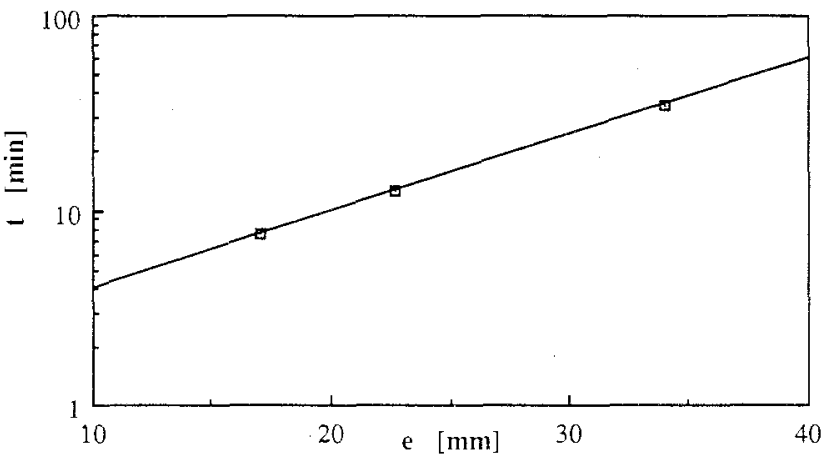

Figure 4.7 - Effect of bark thickness on time needed for cambium temperature to reach $30^{\circ} \mathrm{C}$. Conditions for calculation are the same as in fig. 4.6.

(1963) for lethal temperature.

\section{Concluding Remarks}

The use of prescribed burning inside tree stands is an important silvicultural tool to combat weed and fuel accumulation problems. For this purpose it is essential to predict fire effect on trees with regard to damage and tree resistance. Likewise mortality should be evaluated after the occurence of a wild fire.

In this paper a simple and efficient numerical scheme was presented and validated for the prediction of temperature distribution within a section of a tree trunk subjected to ground fire conditions. Crown fires are thus precluded from the present analysis. Reliable results can be expected provided the time-varying external fire conditions are well known and dimensions as well as thermodynamic properties of the tree tissues exposed to fire are accurately available. Moisture content may be implicitly accounted for provided its influence upon those thermodynamic properties is known. This was here the case for wood but not for bark. After a partial validation the model was applied to the case of a controlled fire inside a Pinus pinaster stand. Bark thickness is seen to be the principal single factor that affects the cambium temperature. Nevertheless other factors like the uneven temperature distribution around tree surface, flame residence time or the bark and wood thermodynamic properties must also be included in any realistic analysis. In general the results obtained are in gond correlation with those available in the literature. Further effort should however be made on the accurate measurement of bark thermodynamic properties for different tree species and environmental conditions.

Acknowledgements. This work was carried under a research project - $86 / 69$ - sponsored by the Junta Nacional de Investigação Científica e Tecnológica (JNICT).

The authors are grateful also to other institutions that support the research program in which the present study is included, namely Serviço Nacional de Bombeiros, Direcção Geral das Florestas, Comissão Nacional Especializada de Fogos Florestais, Instituto Nacional de Meteorologia e Geofísica, Fundação Luso - Americana and ACEL.

\section{References}

Bird, R.B., Stewart, W.E. and Lightfoot, E.N. 1960 Transport Phenomena. John Wiley \& Sons.

Costa, J.J., Oliveira, L.A. and Viegas, D.X. 1988 Distribuição do campo de temperatura no interior de um tronco de árvore em condições de incêndio. Proc. Jorn. Cient. Inc. Flor. Univ. of Coimbra - Portugal.

Davis, K.P. 1959 Forest fire: control and use. McGraw-Hill Book Co. Inc.

De Ronde, C. 1982 The resistance of Pinus species to fire damage. South African Forestry Journal 122: 22.

De Ronde, C. 1988 Preliminary investigations into the use of fire as a management technique in plantation ecosystems of the Cape province. M.Sc. Thesis, University of Natal, Durban, South Africa.

Figueiredo, A.R., Costa J.J. and Raimundo,A. M. 1990 Determinação experimental da condutibilidade térmica Método transitório. Technical Report DEM/TC - 9002. University of Coimbra, Portugal (in preparation).

Gill, A.M. and Ashton, D.H. 1968 The role of bark type in relative tolerance to fire of three central victorian eucalypts. Australian Journal of Botany 16: 491.

Gosman, A.D., Launder, B.E. and Reece, G.J. 1985 Computeraided engineering. Heat transfer and fluid flow. John Wiley and Sons.

Hare, R.C. 1965 Contribution of bark to fire resistance of southem trees. Journal of Forestry 63: 248.

Kayll, A. J. 1963 A technique for studying the fire tolerance of living tree trunks. Canada Deptartment of Forestry, Forest Research Branch. Publication No. 1012: 22 pp.

Koch, P. 1972 Utilization of the southern pines. United States Department of Agriculture, Forest Service.

Kollmann, F.F.P and Cote, W.A. 1968 Principles of wood science and technology. I. Solid wood Springer-Verlag. Berlin. New York.

Martin, R.E. 1963 A basic approach to fire injury of tree systems. Proceedings 2 nd annual Tall Timbers Fire Ecology Conference, 151.

Patankar, S.V. 1980 Numerical heat transfer and fluid flow. Hemisphere, Washington, D.C.

Rego, F. \& Rigolot, E. 1989 Heat transfer through bark: a simple predictive model. Proceedings 3rd International Symposium on Fire Ecology. Freiburg, Germany.

Reifsnyder, W.E., Herrington, L.P. and Spalt, K.W. 1967 Thermophysical properties of bark of shortleaf, longleaf, and red pine. Bulletin $\mathrm{n}^{\mathrm{0}} 70$, School of Forestry, Yale University, New Haven.

Reynolds, E. S. 1939 Tree temperatures and thermostasy. Annual Mississipi Botanical Gardens 26: 165.

Smith, G.D. 1978 Numerical solution of partial differential equations: finite difference methods. Oxford University Press.

Vines, R.G. 1968 Heat transfer through bark, and the resistance of trees to fire. Australian Joumal of Botany 16: 499. 